\title{
A RESIDENTIAL AND EMPLOYMENT CENTRE FOR THE SPINAL DISABLED IN PERTH, WESTERN AUSTRALIA
}

\author{
By E. R. GRIFFIThS, O.B.E., F.R.C.S.(Edin.), F.R.A.C.S. \\ Head of Spinal Department, Royal Perth (Rehabilitation) Hospital, \\ Shenton Park, Western Australia
}

Abstract. In 1969 a Residential and Employment Centre for the spinal disabled was established in Perth, Western Australia, entitled the Quadriplegic Centre. In the past 9 years this has expanded to provide residential accommodation for 75 persons with anticipated accommodation for a total of 95 residents by the end of 1978 . In the employment area the number of employees has risen from Io in 1970 to 190 in 1977, and their production has risen from $\$ 10,700$ to over half a million dollars Australian in the same period.

Key words: Spinal paralysis; Residential accommodation; Employment.

\section{Introduction}

SPINAL paralysis, traditionally a disease 'not to be treated' in the words of Hippocrates, generally carried with it a death sentence either early on in the acute phase, or in the early weeks thereafter from urinary infections and renal failure, or from gross suppurating decutibus ulcers. This was the common fate of most paraplegics and of all tetraplegics before the pioneer work of Sir Ludwig Guttmann at Stoke Mandeville, just over 30 years ago.

The hardy survivors who remained, were condemned to a life of chronic invalidism, often developing gross deformities. The fortunate were confined to their homes under the care of their well-meaning but ill-informed relations, and the less fortunate to institutions. The poor health of this surviving group made employment not to be considered.

The first spinal injuries centre in Australia was established in Perth in 1954 at the Royal Perth Rehabilitation Hospital. This has now developed into a wellknown centre internationally, with a programme extending from reception of acute cases through rehabilitation to a stage of independence where feasible, and return to the community in habitat and employment.

\section{Residential Accommodation}

The best place to live, for any man or woman, is in their own home. Any institution, however good, can only be second best. We endeavour to return all our patients to their home if their residual disability can be rehabilitated to a stage of independence with or without the assistance of parents, husband or wife, whichever the case may be, or of relatives. The home is inspected by a Domiciliary Nursing Service and our Occupational Therapists before the patient is discharged. Structural alterations required for access to the home and movement within the home, including all alterations to bathroom, shower and toilet areas, are prescribed by the para-medical and nursing personnel who have expert knowledge as to what is needed for the particular patient concerned. The alterations are itemised, 
contracts are put out for tender, and the work is then carried out by the successful contractor. This is put in hand well before the patient's anticipated date of discharge, so that alterations should be complete and the home suitable for residence before the patient is discharged from hospital.

Fortunately, we have an enlightened State Government in Western Australia who appreciate very well that it is far cheaper to subsidise a person living in his home than to maintain him in a hospital bed with all the cost of nursing and medical attention that this involves. Our State Government now accepts liability for costs up to, and in some cases over, $\$ 2,000$ (Australian) for such alterations to the home where no other funds are available and the patient would otherwise be confined to an institution.

Accordingly, the vast majority of our patients, even those with considerable disability, do return to their home within the community and reside there with the assistance of domestic nursing services.

\section{Quadriplegic Centre}

Certain patients, however, are unable to return home. These fall into several categories:

I. The paraplegic with no settled home or family, 2. the tetraplegic who is unmarried and with aged parents unable to render physical assistance, 3. the paraplegic or tetraplegic whose marriage has broken down following injury, and 4. the spinal disabled from remote country areas who need to reside within the metropolitan area to carry on any form of employment which is not available for them in rural areas.

Our residential and employment centre is called the Quadriplegic Centre for Western Australia.

We commenced building in 1968 and our centre was opened in 1969; the first stage being that of a 34-bed centre with a small workshop where we hoped to employ the disabled. Funds were made available by the efforts of our charitable body, the Paraplegic-Quadriplegic Association of Western Australia, together with Federal and State Government subsidy. Two hectares of Crown land were given to us by the State Government on a site adjacent to the Royal Perth Rehabilitation Hospital some $7 \mathrm{~km}$ from the city centre. Since the first grant of land a further 3 hectares of land have been allocated to us by the State Government, making a total of 5 hectares, i.e. more than I 2 acres of land now available for development. Our intention was to make this a modern centre with the best of nursing and medical facilities where our patients, many of whom were in the younger age group, could lead a pleasant life commensurate with their severe disability, and also to regain self-respect by being once more employed in a profitable capacity and maintain themselves by supplementing a Government awarded Social Security pension.

As this was the first centre of its type in Australia, we had nothing in the way of expertise to call upon in our planning, and of course made many minor mistakes, though the whole concept remained very adequate for its needs. I myself, was Chairman of the Building Committee of the first stages, and used many paraplegic and quadriplegic patients to guide me as to essential matters such as the selection of electric light switches that could be operated by tetraplegics; doorways which would be negotiable for them unaided, and of course the choice of a single room or a shared one with a friend.

As our centre developed on the residential site, we have added on many I $7 / 4$-C 


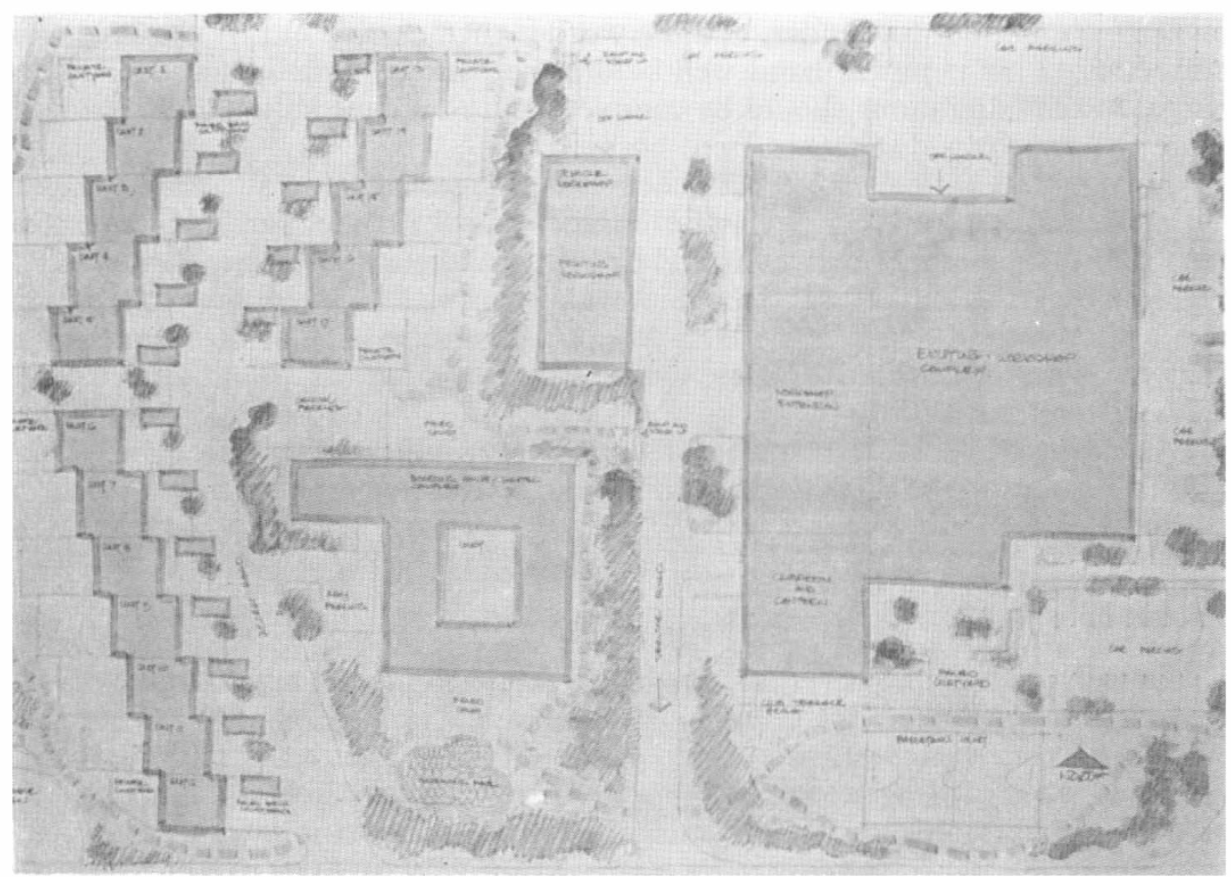

FIG. I

Architect's plan of the Quadriplegic Centre showing residential areas completed, and initial workshop.

sections year by year, until we now have accommodation for 75 residents, 47 of them being in single rooms, the remainder in rooms accommodating two people. Building is already in hand for a further I8-bed extension, giving us accommodation for more than 90 clients by the end of this year. We have a hospital centre of some 40 beds where intensive nursing management can be carried out for those with severe disabilities, and the remainder are for those who require minimal or little nursing care, and can be independent to a greater or lesser degree. The physical care of the patients is managed by some 40 nursing personnel. Physiotherapy services are available, and an honorary medical officer attends on a daily basis and is on call at night and weekends for any medical emergency.

We have planned our buildings in separate sections of eight- or ten-room blocks, each with its own communal facilities such as a dining-room, kitchen and lounge so that there may be a feeling of community within each small section, and there are many recreation rooms for relaxation where different groups may meet for their own special activities.

Our workshop initially employed some I2 workers, but it was found after 2 years to be too small, and was extended. After 2 more years further extensions were required, and today a completely new workshop has been built and opened in September 1976, which will accommodate some 250 workers all told. The majority of these come from their homes for employment and return to their homes daily, and more than two-thirds of the residents of the Centre are employed there.

The previous workshop which we had outgrown in some 7 years after opening the Centre, was then converted into an Activity Therapy Centre where there is at 
PAPERS READ AT THE ANNUAL SCIENTIFIC MEETING, I 978

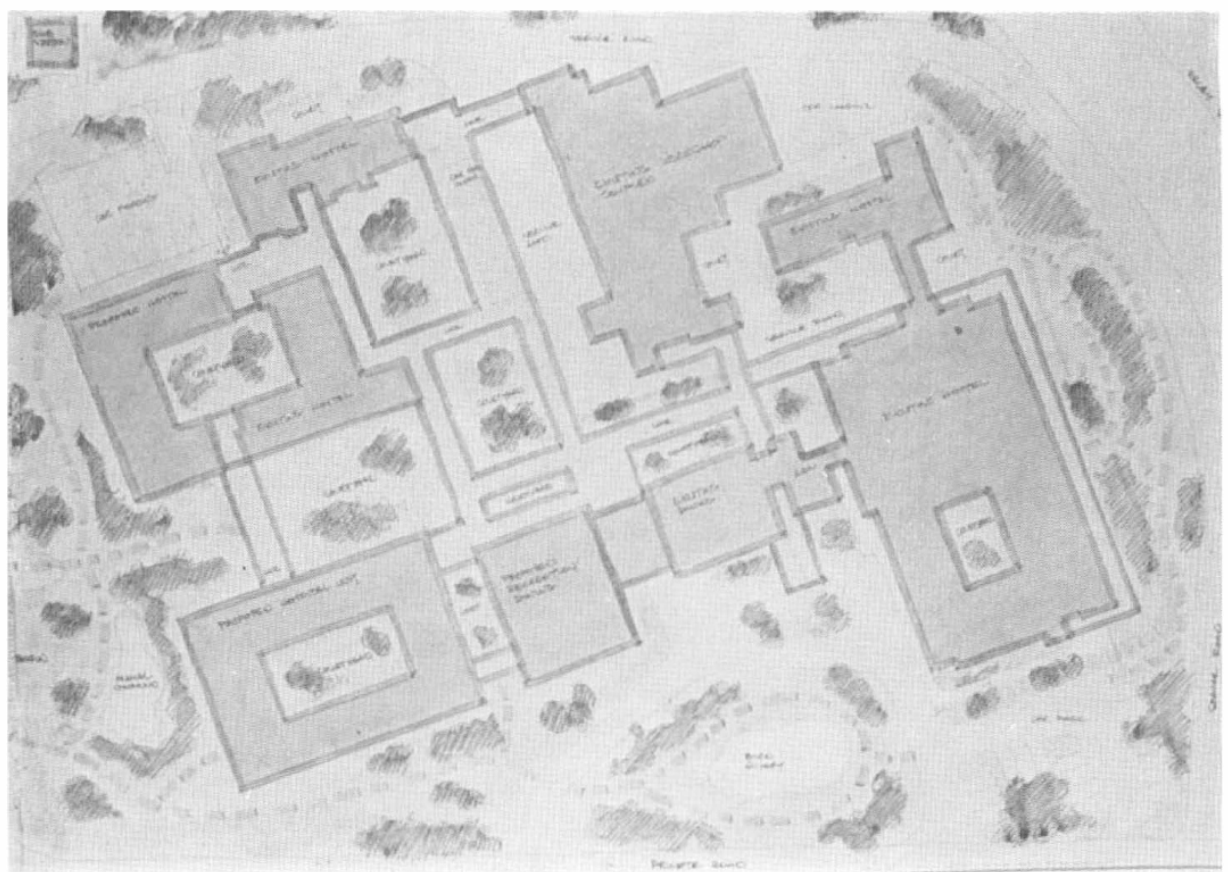

FIG. 2

Architect's plan of future projection of development of new workshop now completed, and further residential accommodation for married couples still pending.

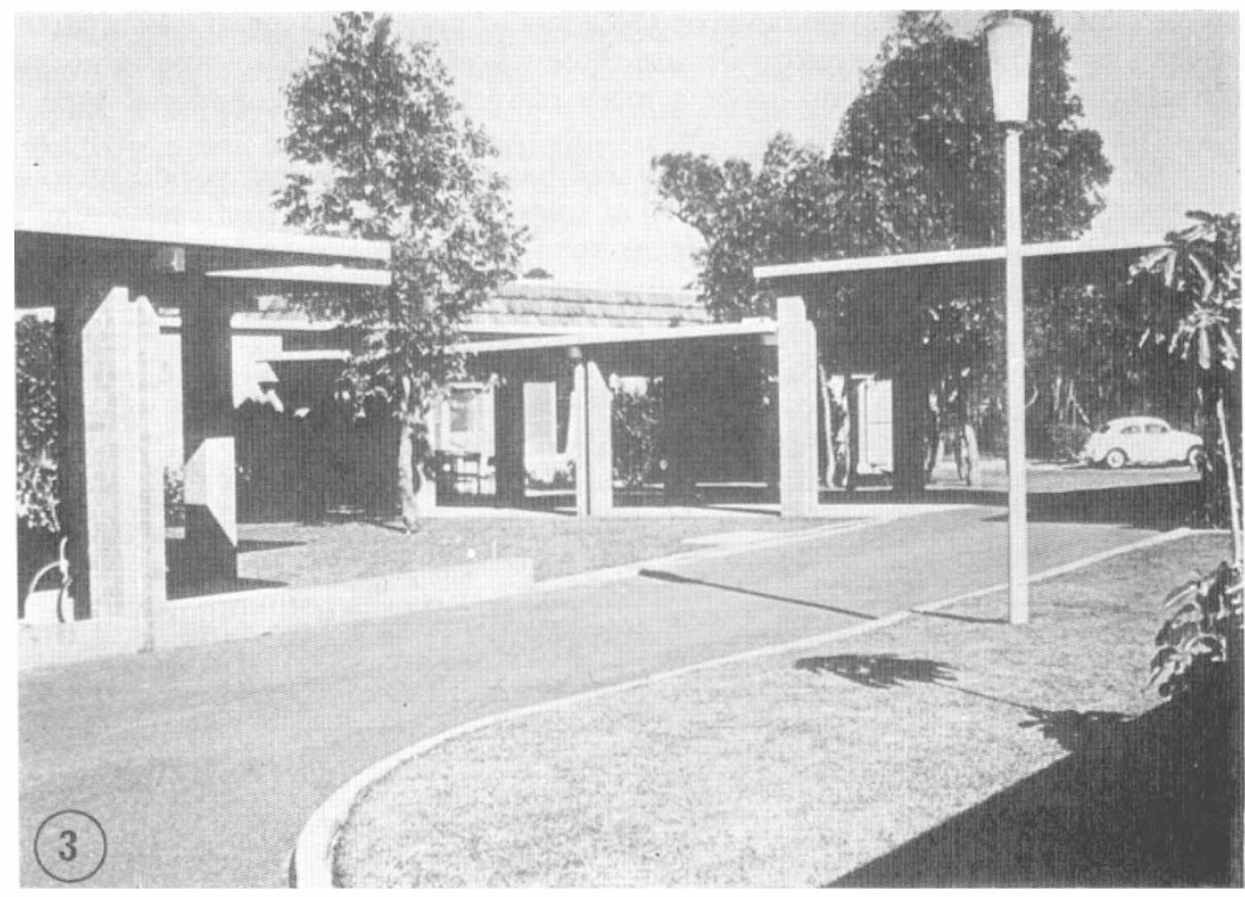

FIG. 3

Entrance to Quadriplegic Centre. 


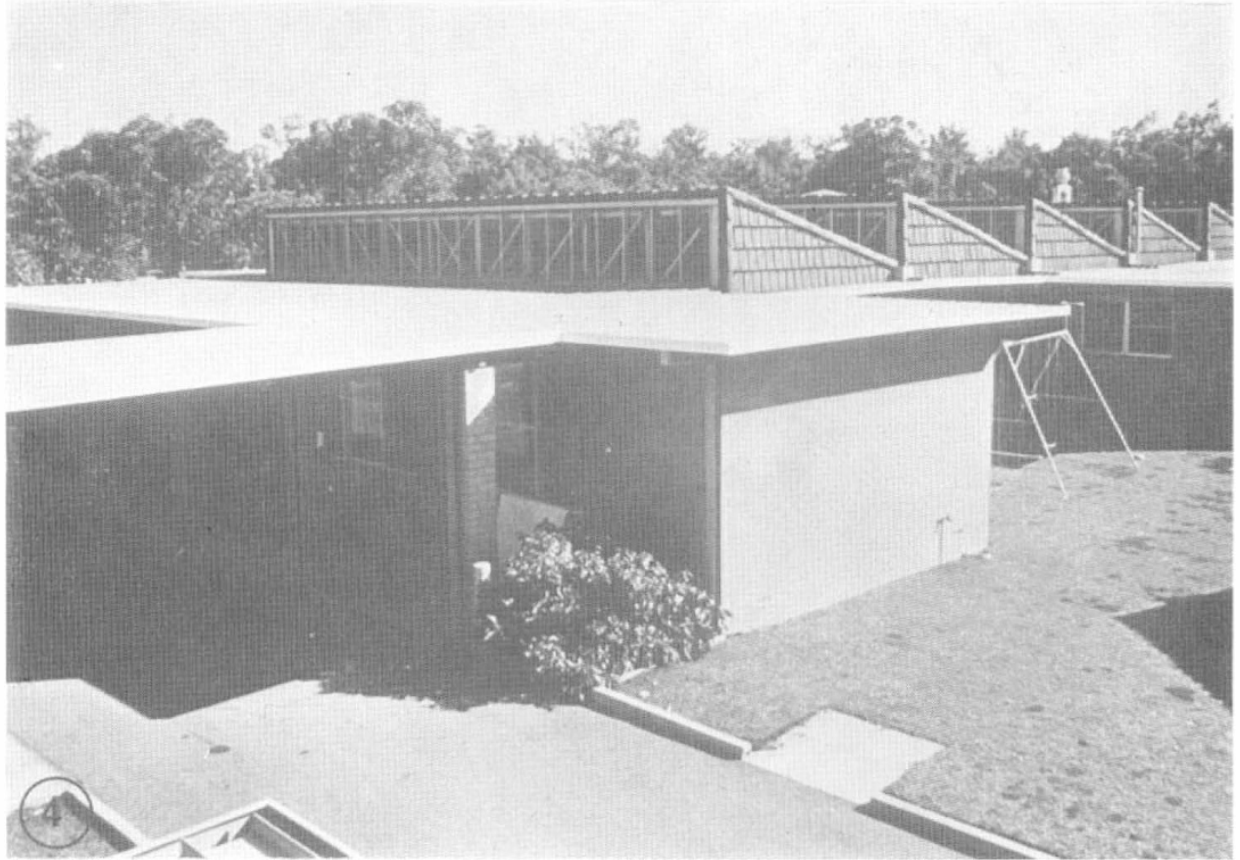

FIG. 4

Initial workshop.

the present time a daily attendance of 58 clients or patients, many of whom attend from their homes and the remainder are those who cannot be employed in normal workshop activities or who choose a more recreational or occupational type of activity voluntarily.

Table I shows how the workshop area has extended over a period of some 9 years, with a production figure overall of some $\$ 10,000$ in the first year, rising to over half a million dollars Australian in 1977. This workshop is known as the Para-Quad Industries, and though subsidised to a certain extent by the parent

TABLE I

Para-Quad Industries-Production 1970-I977

\begin{tabular}{|c|c|c|}
\hline Year & $\begin{array}{l}\text { Production } \\
\$\end{array}$ & $\begin{array}{c}\text { Disabled } \\
\text { employees }\end{array}$ \\
\hline 1970 & 10,763 & IO \\
\hline I97I & 24,478 & 23 \\
\hline I972 & 53,903 & 45 \\
\hline I973 & 75,397 & 60 \\
\hline 1974 & 133,073 & $8 I$ \\
\hline I975 & 271,233 & IIO \\
\hline 1976 & 402,885 & 160 \\
\hline I977 & 532,297 & I90 \\
\hline I978 (to 3I March) & I 47,477 & 193 \\
\hline
\end{tabular}


Paraplegic-Quadriplegic Association, must compete for contracts for work with other bodies in the State and get very little preferential treatment from governmental bodies for its award of contracts and employment.

The type of employment is very varied, from simple bench packaging work to furniture manufacture, heavy industrial welding and metalwork, a very large printing section which carries out the entire production for a large business organisation in Western Australia, and in the last year an electronic section which has hopes to expand vigorously in the coming year.

For those who do not wish to work indoors in an industrial atmosphere, there is a large garden and nursery section where plants are prepared from seeds up to the stage of potting out, and then are retailed to the public as a garden supply. One interesting point here is that plants are also rehabilitated, as indoor plants from many office buildings in the city area requiring a breath of fresh air are taken into the nursery section, replacements supplied, and the original plant given a spot of sunshine and tender loving care before resuming its busy city life again.

Table II shows that it is still very difficult to employ a complete tetraplegic profitably, but our incomplete tetraplegics are employed to the extent of 87 per cent of our case load, and in our paraplegics the vast majority of those who wish to work are doing so. Those tetraplegics who are complete and at a high level, are employed also in the Activity Therapy Centre for many hours daily as far as their physical tolerance will permit, and find interest and social intercourse in the development of the talents in the arts and crafts again with the assistance of trained staff. In all, then, some 250 personnel are occupied in either the Para-Quad Industries Workshop or in the Activity Therapy Centre.

Our future plans over the next 5 years involve further hospital accommodation, a heated indoor swimming pool, married quarters and motel units for interstate and rural visitors.

We have, then, built a centre which has proved its worth in affording pleasant accommodation and profitable employment to those with major spinal disabilities.

We think we have succeeded to a certain extent in affording a reasonable lifestyle to patients with a major disability. We have had only two patients with depression and suicidal tendencies since our centre opened, and our residents have now formed a community with their own self-elected committee to advise the management on the residents' requirements for employment and to arrange social functions. They have by their own efforts raised enough funds to purchase a mini bus suitably adapted for wheelchairs in which they carry out visits to concerts in the city area, visits to country areas, conduct barbecues and other social gatherings in the grounds of the Centre, which are well set out in a garden atmos-

TABLE II

Employment of follow-up patients with traumatic injuries

\begin{tabular}{lccccc}
\hline Level of lesion & \multicolumn{2}{c}{ Cervical } & \multicolumn{2}{c}{ Thoraco-lumbar } \\
\cline { 5 - 6 } Severity of lesion & Complete & Incomplete & Complete & Incomplete \\
\hline Working & 5 & 72 & 68 & 45 \\
Not working & 33 & I I & 2 I & 9 \\
Total & 38 & 83 & 89 & 54 \\
$\%$ Working & $13 \%$ & $87 \%$ & $75 \%$ & $82 \%$ \\
\hline
\end{tabular}


phere. The Annual Dinner of the Association is a great event, and always attended by the Senior Medical Staff and by a Minister of the State Government.

We have tried not only to prolong life in our patients with severe disability, but to make their life worthwhile with the prospect of employment in a sheltered atmosphere, reasonable living conditions and a social and cultural life as good as can be accepted within their physical disability.

Our buildings are modern, and our workshop activities geared to the Australian way of life and market demands. There is no reason, however, why the basic principles of residential accommodation and employment should not be carried out in other countries to suit their separate cultures and work requirements. This has been well shown in the Paraplegic Village in Solo in Central Java under the impetus of the late Professor Dr Soeharso, and later in Jakarta itself, where a new spinal unit has been developed with very worthwhile cooperation between Western Australia and Jakarta, and is now under the control of Dr Tajib Salim, who spent more than a year with us in Perth. Similarly, in India, Colonel Amarjit Chahal, who spent a very happy year with us in Perth, has developed a similar centre in Poona, where his Paraplegic Home is developing into an excellent centre which I believe should be regarded as a model for further centres of this nature in India's vast population. Colonel Chahal has similarly developed his facilities for residents, for transportation and for employment to those required and accepted by the castes of his own country.

In Asia and South-East Asia there are great problems in terms of vast populations, lack of sophisticated and industrialised society, and these problems sometimes seem insuperable. No doubt the vast majority of patients with spinal injury in many of these countries never reach hospital, and certainly not a spinal centre, but once having reached expert care, it is our duty not only to preserve life but to make that life as fruitful and rewarding as there are means to do so by providing an acceptable place of residence according to the culture of the country, and employment that can restore self-respect and the feeling of worth. I remember the words one young quadriplegic man spoke to me some years ago when he had been at home for nearly Io years, existing but doing nothing more, when he asked me, 'Why did you keep me alive?'

Our first objective then, must still be to preserve life in cases of major spinal injury. Our second objective must be to provide facilities for that life to be worthwhile.

\section{SUMMARY}

A residential and employment centre for spinal disabled developed in Perth, Western Australia, has been described. It has been acknowledged that the best place of residence for any citizen is within his own home and returning to the community at large. Where this is not possible for reasons outlined in the article, we have endeavoured to provide a place of residence as pleasant as possible and provide the amenity of employment to the best extent that the disabled person's potential permits. Two similar centres in other developed countries demonstrate that such centres are feasible and may become economically viable. Employment offered in Perth varies from industrial production to horticultural, depending upon the aptitude and personal desires of the disabled person. It is emphasised that prolongation of life alone is not adequate but that the life style offered must be fulfilling and worthwhile. 


\section{RÉSUMÉ}

Cet article décrit une résidence et un centre d'emploi créés à Perth, en Australie Occidentale, pour les infirmes atteints à l'épine dorsale. Il est reconnu que la meilleure habitation pour un citoyen est sa propre maison et pour lui de se joindre à la societé en général. Quand cela n'est pas possible, pour les raisons données dans l'article, nous essayons de procurer à la personne incapacitée une residence aussi agréable que possible et de le pourvoir de facilités d'emploi adaptées au mieux à ses qualités. Deux centres similaires ouverts dans d'autres pays développés se sont avérés pratiques et économiquement viables. Les offres d'emploi à Perth varient de la production industrielle à l'horticulture, selon les aptitudes et les goûts de chaque personne incapacitée. Il faut souligner que la prolongation de la vie seulement n'est pas suffisante, mais que le genre de vie offert doit être satisfaisant et valant la peine.

\section{ZUSAMMENFASSUNG}

Wir haben ein Wohn-und Arbeitszentrum in Perth-Western Australien beschrieben. Es ist allgemein bekannt, dass der beste Platz fuer alle Buerger sein eigenes Haus ist und die Rueckehr zur allgemeinen Umwelt. Wo dies nicht moeglich ist, wie dies in dem vorhergehenden Artikel erwaehnt wurde, haben wir versucht einen Wohn platz zu schaffen so gut wie moeglich und Arbeitsgelegenheiten zur vollen Auswertung der Faehigkeiten des Koerperbehinderten. Zwei aehnliche Zentren in Entwicklungslaendern haben bewiesen, dass diese Zentren moeqlich sind und wirtschaftlich produktive sein koennen. Arbeitsgelegenheiten in Perth rangieren von industrialer Produktion zu Gartenanbau (Hortikultur), dies haengt von den Faehigkeiten und den persoenlichen Wuenschen des Koerperbehinderten $\mathrm{ab}$. Es wird betont, dass die Lebensverlaengerung allein nicht genug ist, sondern dass der Lebensinhalt der geboten wird, zufriedenstellend und belohnend sein muss. 